\title{
Up-regulation of hTERT expression by low-dose cisplatin contributes to chemotherapy resistance in human hepatocellular cancer cells
}

\author{
XIAN-LING GUO ${ }^{1,2^{*}}$, NAN-NAN MA ${ }^{1 *}$, FEI-GUO ZHOU ${ }^{1}$, LI ZHANG $^{1}$, XIN-XIN BU ${ }^{1}$, \\ KAI SUN ${ }^{1}$, JIAN-RUI SONG ${ }^{1}$, RONG LI ${ }^{1}$, BAI-HE ZHANG ${ }^{1}$, MENG-CHAO WU ${ }^{1}$ and LI-XIN WEI ${ }^{1}$ \\ ${ }^{1}$ Tumor Immunology and Gene Therapy Center, Eastern Hepatobiliary Surgery Hospital, \\ The Second Military Medical University, Shanghai; ${ }^{2}$ Hang Zhou Sanitarium of PLA, Zhejiang, P.R. China
}

Received March 24, 2009; Accepted May 20, 2009

DOI: $10.3892 /$ or_00000470

\begin{abstract}
The telomerase is specifically activated in most malignant tumors but is usually inactive in normal somatic cells. It has been reported that telomerase has an anti-apoptotic role and up-regulation of telomerase helps cancer cells to be resistant to chemotherapeutic agent-induced cell death. The effect of cisplatin on telomerase activity is complex, and the exact mechanism remains largely unknown. In this study, we found that cisplatin activated telomerase activity and human telomerase reverse transcriptase (hTERT) expression in SMMC7721 human hepatocellular carcinoma cell line. Lowdose cisplatin up-regulated hTERT and NF- $\mathrm{KB}$ p65 expression and increased telomerase and NF- $\mathrm{KB}$ activity. Inhibition of $\mathrm{NF}-\kappa \mathrm{B}$ attenuated the hTERT expression and telomerase activity exposed to cisplatin, suggesting that NF- $\kappa \mathrm{B}$ is responsible for the cisplatin-induced activation of the hTERT. Furthermore, preincubation of low-dose cisplatin which induced high expression of hTERT help hepatocellular carcinoma SMMC7721 cells survive under the high concentration of anti-cancer drugs. Inhibition of hTERT increased sensitivity of SMMC7721 cells to chemotherapy. Taken together, these results suggested that up-regulation of hTERT expression by low-dose cisplatin is NF- $\mathrm{KB}$-dependent and
\end{abstract}

Correspondence to: Dr Li-xin Wei, Tumor Immunology and Gene Therapy Center, Eastern Hepatobiliary Hospital, The Second Military Medical University, 225 Changhai Road, Shanghai 200438, P.R. China

E-mail: lixinwei@smmu.edu.cn

*Contributed equally

Abbreviations: HCC, human hepatocellular cancer; hTERT, human telomerase reverse transcriptase; 5-FU, 5-fluorouracil; H3, Histone $\mathrm{H} 3$; PDTC, pyrrolidine dithiocarbamate

Key words: hepatocellular carcinoma, cisplatin, telomerase, human telomerase reverse transcriptase, $\mathrm{NF}-\mathrm{\kappa B}$ contributes to chemotherapy resistance in human hepatocellular cancer cells.

\section{Introduction}

Telomerase is a cellular reverse transcriptase that catalyses the synthesis and extension of telomeric DNA $(1,2)$. This enzyme is specifically activated in most malignant tumors but is usually inactive in normal somatic cells $(3,4)$. The catalytic core of human telomerase is composed of an RNA subunit known as hTER (human telomerase RNA) and a protein subunit named as hTERT (human telomerase reverse transcriptase). Although the RNA subunit (hTR) of the human telomerase complex is constitutively expressed in both tumor and normal somatic tissues, expression of the catalytic subunit (hTERT) correlates with telomerase activity and is a key step of activation of telomerase (5-7). Substantial experiments demonstrate that the transcriptional regulation of hTERT expression represents the primary and rate-limiting step in the activation of telomerase activity in most cells (8-11). Several studies have indicated that hTERT has an anti-apoptotic activity in addition to its role in telomere length maintenance $(12,13)$.

Chemotherapeutic drugs have complex effects on telomerase activity and these complex effects are cell typedependent (14-19). Cisplatin is a DNA cross-linking agent used in the treatment of various tumors including hepatocellular carcinoma $(20,21)$. Human testicular cancer cells treated with lethal doses of cisplatin exhibit decreased telomerase activity (22). In leukemic cells, telomerase activity was also downregulated after treatment with cisplatin (23). Additionally, long-term exposure of colorectal carcinoma cells to cisplatin results in increased telomerase activity (18). However, the exact mechanism of the complex effect of cisplatin on telomerase activity remains largely unknown.

In this study, we examined the effect of low-dose cisplatin on telomerase activity in the human hepatocellular cancer (HCC) cell line, SMMC7721. We treated SMMC7721 cells with various doses of cisplatin and examined telomerase activity and hTERT expression. A dose-dependent upregulation of telomerase activity and hTERT expression were observed. Preincubation with low-dose cisplatin reduced chemosensitivity of SMMC7721 cells to chemotherapeutic 
agents. Furthermore, inhibition of hTERT increased chemosensitivity of SMMC7721 cells to chemotherapeutic agents. Thus we concluded that up-regulation of hTERT expression by low-dose cisplatin contribute to chemotherapy resistance in human hepatocellular cancer cells.

\section{Materials and methods}

Cell culture and reagents. Human HCC SMMC7721 cells were maintained in RPMI-1640 containing $10 \%$ fetal bovine serum. The cells were incubated at $37^{\circ} \mathrm{C}$ and $5 \% \mathrm{CO}_{2}$. Cisplatin, 5-FU and epirubicin were purchased from QILU PHARMA (Jinan, Shandong, China). PDTC was obtained from TOCRIS (Ballwin, MO, USA). The anti-GAPDH and anti-H3 were obtained from Cell Signaling Technology (Beverly, MA, USA). The anti-TERT and anti-p65 antibodies were purchased from Santa Cruz Biotechnology, Inc. (Santa Cruz, CA, USA). The anti- $\beta$-actin was obtained from Sigma (St. Louis, MO, USA).

Plasmids. hTERT promoter luciferase reporter plasmid (pGL3B-TRTP) was a gift from Dr Jiyue Zhu (24). NF-кB plasmid, IKK-KM (a kinase inactive mutant of murine IKKß) plasmid were kind gifts from Dr Chuanshu Huang (25).

Cell viability and cell apoptosis. The measurement of viable cell mass was performed with a Cell Counting Kit (Dojin Laboratories, Kumamoto, Japan) to count living cells by WST-8. Cells were seeded $\left(0.5 \times 10^{4}\right.$ cells per well $)$ on a $96-$ well plate and the cells were treated with indicated concentration of 5-FU and epirubicin for $24 \mathrm{~h}$ with or without preinfection with AD-si/hTERT. For quantitative analysis of cell viability, $10 \mu 1$ of a Cell Counting Kit- 8 solution was added to each well, and, after incubation at $37^{\circ} \mathrm{C}$ for $2 \mathrm{~h}$ in a humidified $\mathrm{CO}_{2}$ incubator, absorbance at $450 \mathrm{~nm}$ was monitored with a microplate reader (Synergy HT, Bio-Tek, USA). The values obtained were normalized to those of control cells incubated with vehicle only. Assessment of apoptosis based on nuclear morphology using DAPI staining. Briefly, cells in which the nucleus contained clearly condensed chromatin or cells exhibiting fragmented nuclei were scored as apoptotic. Apoptotic data are reported as percentage apoptosis, obtained by determining the numbers of apoptotic cells vs. the total number of cells. For each sample, a minimum of 5 counts involving a minimum of 100-200 cells/count were scored. Apoptotic data are presented as the mean \pm SD for three independently performed experiments.

Luciferase assay. Plasmids were transiently transfected using Lipofectamine 2000 reagent (Invitrogen, Carlsbad, CA, USA), according to the manufacturer's protocol. The IKK-KM plasmid was cotransfected with pGL3B-TRTP plasmid to determine the effect of NF- $\mathrm{\kappa B}$ inhibition on the activation of hTERT. Cells were harvested and subjected to luciferase assays using the Dual Luciferase Reporter Assay System (Promega, WI, USA). A Renilla luciferase plasmid was also cotransfected in each experiment to serve as an internal control for transfection efficiency. The relative luciferase activity reported herein is the average of the three resultant values.
Telomerase activity assay. Telomerase activity was measured using a PCR-based telomeric repeat amplification protocol (TRAP) enzyme-linked immunosorbent assay (ELISA) kit (Boehringer Mannheim, Mannheim, Germany) according to the manufacturer's description. In brief, cells were lysed in $200 \mu 1$ lysis reagent and incubated on ice for $30 \mathrm{~min}$. For the TRAP reaction, $2 \mu \mathrm{l}$ of cell extract (containing $2 \mu \mathrm{g}$ protein) was added to $25 \mu \mathrm{l}$ of reaction mixture with the appropriate amount of sterile water to make a final volume of $50 \mathrm{ml}$. PCR was performed in a Mastercycler as follows: primer elongation $\left(30 \mathrm{~min}, 25^{\circ} \mathrm{C}\right)$, telomerase inactivation $\left(5 \mathrm{~min}, 94^{\circ} \mathrm{C}\right)$ and product amplification by the repeat of 30 cycles $\left(94^{\circ} \mathrm{C}\right.$ for $30 \mathrm{sec}, 50^{\circ} \mathrm{C}$ for $30 \mathrm{sec}, 72^{\circ} \mathrm{C}$ for $90 \mathrm{sec}$ ). Hybridization and the ELISA reaction were carried out following the manufacturer's instructions. As positive control for the assay, extracts from HEK293 cells were used and cell lysates were heatinactivated for $10 \mathrm{~min}$ at $85^{\circ} \mathrm{C}$ also used as negative controls. Absorbance values are reported as the $\mathrm{A} 450 \mathrm{~nm}$ reading after subtraction of the control value.

$R T$-PCR for hTERT. Expression of hTERT was analyzed by RT-PCR. Briefly, total RNA was isolated from the cells using TRIzol (Invitrogen) according to the manufacturer's protocol. cDNA was synthesized from $2 \mu \mathrm{g}$ total RNA using the Moloney murine leukemia virus reverse transcriptase (Promega) with Oligo $(\mathrm{dT})_{18}$. Two-microliter aliquots of cDNA were used for PCR amplification employing the following setting: $30 \mathrm{sec}$ at $94^{\circ} \mathrm{C}, 30 \mathrm{sec}$ at $58^{\circ} \mathrm{C}$ and $30 \mathrm{sec}$ $72^{\circ} \mathrm{C}$ for hTERT and $\beta$-actin with 32 cycles. The primer pairs were used: 5'-CGGAAGAGTGTCTGGAGCAA-3' (LT5) and 5'-GGATGAAGCGGAGTCTGGA-3' (LT6) for hTERT (26) and 5'-TGACGGGGTCACCCACACTGTGCC CATCTA-3' and 5'-CTAGAAGCATTGCGGTGGACGAT GGAGGG-3' for $\beta$-actin.

Western blot analysis. Protein extracts were prepared with the Active Motif nuclear extract kit (Active Motif, Carlsbad, CA, USA). Protein concentrations were estimated using Bradford Protein Assay. Equal amounts of proteins $(30 \mu \mathrm{g})$ were separated by SDS-polyacrylamide gel electrophoresis (PAGE) and transferred onto nitrocellulose membranes. After blocking with $5 \%$ non-fat dry milk in TBS containing $0.2 \%$ Tween-20, membranes were incubated at $4^{\circ} \mathrm{C}$ overnight with various primary antibodies. The immunoblots were visualized with horseradish peroxidase-conjugated goat anti-rabbit or anti-mouse immunoglobulin by using ELC chemiluminescence substrate system (Amersham Biosciences, Piscataway, NJ, USA).

Construction of Ad-si/hTERT. RNA polymerase III H1-RNA gene promoter was used in our study. Designation of siRNA was modified base on the published data by Masutomi. The 64 nt oligo nucleotides encoding hTERT-specific siRNA were 5'-GATCCCCTTTCATCAGCAAGTTTGGATTCAA GAGATCCAAACTTGCTGATGAAATTTTTGGAA-3' and 5'-GGGAAAGTAGTCGTTCAAACCTAAGTTCTCTAGG TTTGAACGACTACTTTAAAAACCTTTTCGA-3'. These oligonucleotides were annealed and ligated into the $B g l \mathrm{II} /$ HindIII sites of pSUPER-EGFP (gift from Dr Li Lin) and the targeted sequence in the recombined vector was confirmed 
A

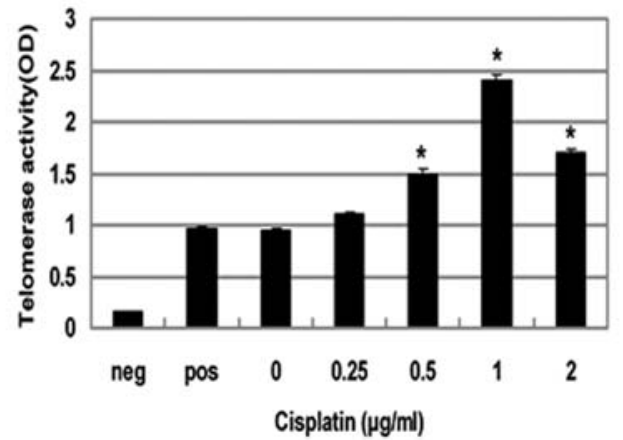

B

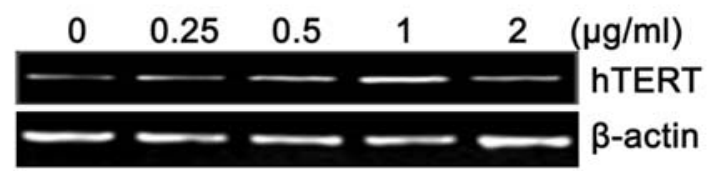

C

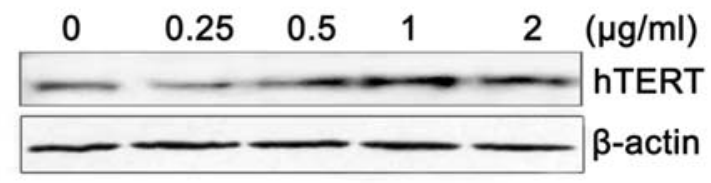

$\mathrm{D}$

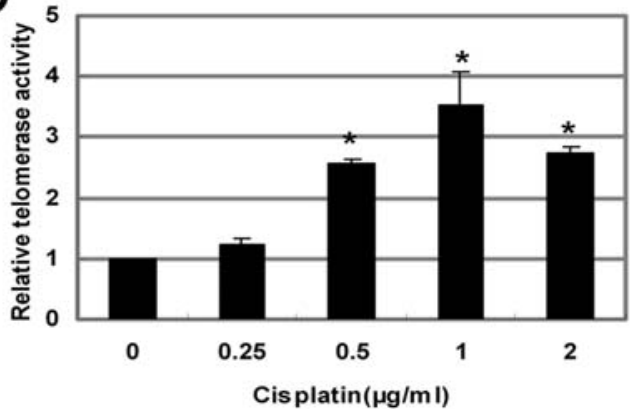

Figure 1. Cisplatin induces telomerase activity and hTERT expression in human HCC cells. (A) HCC SMMC7721 cells were treated with different concentrations of cisplatin for $24 \mathrm{~h}$ and subjected to TRAP-ELISA assays to assess telomerase activity. A representative example of an experiment that was repeated three times is shown. (B) HCC SMMC7721 cells were incubated with different concentration of cisplatin for $24 \mathrm{~h}$ and then harvested to prepare cell lysates. The lysates were subjected to SDS-PAGE and blotted with anti-TERT antibody. (C) RT-PCR assays to examine the effects of cisplatin on the expression of hTERT. HCC SMMC7721 cells were incubated with indicated concentration of cisplatin. After 24 h, RNA was extracted and RT-PCR assays were performed to detect hTERT mRNA. A representative example of an experiment that was repeated three times is shown. (D) HCC SMMC7721 cells were transfected with pGL3B-TRTP plasmid and incubated with indicated concentration of cisplatin. After $24 \mathrm{~h}$, the cells were collected and luciferase assays were performed. The luciferase activity in control samples was normalized to 1.0. Error bars indicate standard deviations. The values shown represent the mean of at least three separate experiments. Significant differences are indicated by asterisks. ${ }^{*} \mathrm{P}<0.05$. Neg, negative control and pos, positive control.

by automatic sequence analysis. The fragment carried H-1 promoter and the target sequence was inserted into the XbaI/HindIII site of pAd-TRACK to generate TRACK-si/ hTERT after adjusting the enzyme cutting site in pCDNA3.1 (+). Then TRACK-si/hTERT was linearized with PmeI and transfected into BJ-5183 cells which carry the adenovirus backbone vector pAd-Easy1. Recombined viral genome was linearized with PacI and transfected into HEK-293 cells in a 6-well plate using lipofectamine 2000 (Invitrogen). Seven days after transfection, the recombinant viruses were collected and subjected to the first round of amplification in a T-25 flask and then purified by $\mathrm{Cscl}$ after two further rounds of amplification. The titer was then determined by Plaque Formation Assay.

Statistical analysis. Values were expressed as the mean \pm standard deviation (SD). Differences in luciferase activity were analyzed by Student's t-test. A p-value $<0.05$ was considered to be significant.

\section{Results}

Low-dose cisplatin induces up-regulation of telomerase activity and hTERT expression. Cisplatin is a widely used anti-cancer agent. To examine the effects of cisplatin on telomerase activity, human HCC cells SMMC7721 were treated with various concentrations of cisplatin for $24 \mathrm{~h}$. Telomerase activity was found to reach a plateau at $1 \mu \mathrm{g} / \mathrm{ml}$ and declined thereafter (Fig. 1A). Western blot analysis and semiquantitative RT-PCR assay were performed to examine whether activation of telomerase by cisplatin was due to up-regulation of the hTERT expression. Treatment of SMMC7721 cells with indicated concentrations of cisplatin for $24 \mathrm{~h}$ led to up-regulation of hTERT protein and hTERT mRNA (Fig. 1B and C). To examine the effect of cisplatin on the transcriptional activity of the hTERT promoter, luciferase assay in which hTERT luciferase reporter plasmid (pGL3B-TRTP) was transfected into SMMC7721 cells was performed. Cisplatin increased the transcriptional activity of the hTERT promoter for up to 3.5-fold (Fig. 1D). These results suggest that cisplatin can induce the hTERT expression at transcriptional level.

Low-dose cisplatin-induced hTERT expression is $N F-\kappa B$ dependent. It has been reported that the regulation at the transcriptional level plays an important role in hTERT gene expression. Sequence analysis has revealed that the hTERT promoter contains many transcriptional factor binding sites including c-Myc, Spl, NF-кB and others $(8,9,11)$. Cisplatin was reported to induce activation of NF- $\mathrm{BB}$ in various cancer 
A

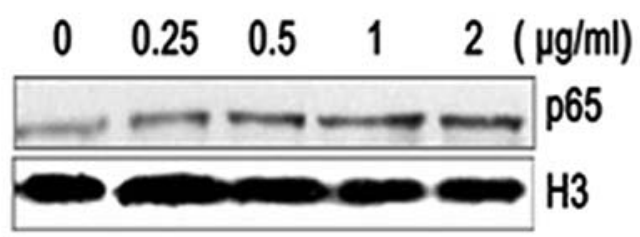

B

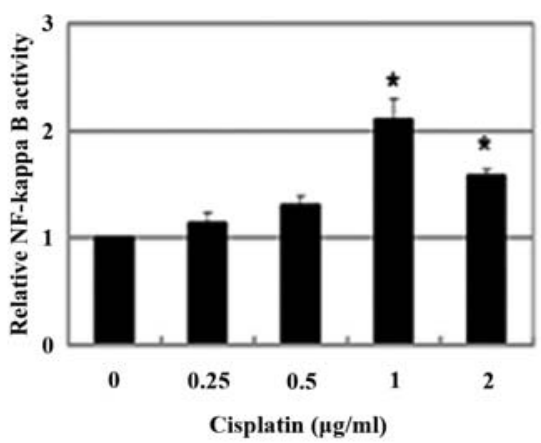

C

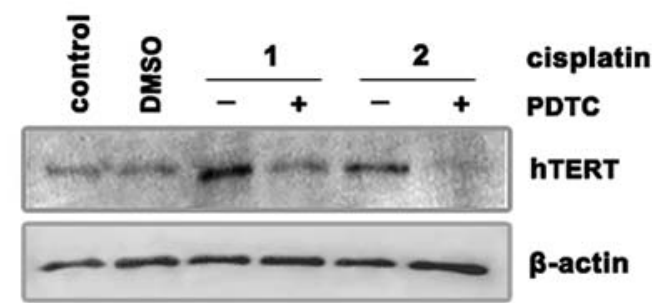

D

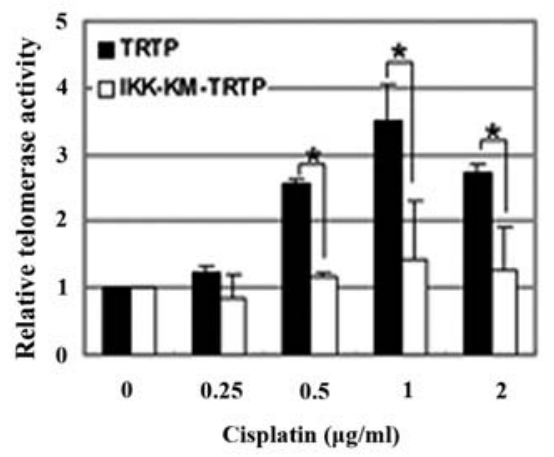

$\mathrm{E}$

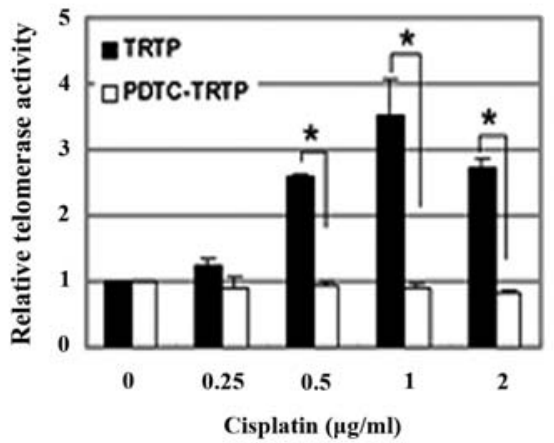

Figure 2. NF-кB involves in cisplatin-induced telomerase activation. (A) HCC SMMC7721 cells were incubated with indicated concentration of cisplatin for $24 \mathrm{~h}$ and then harvested to prepare cell lysates. The lysates were subjected to SDS-PAGE and blotted with anti-p65 antibody. H3 (Histone H3), as loading control of nuclear protein. (B) HCC SMMC7721 cells were transfected with NF-кB luciferase reporter plasmid and incubated with indicated concentration of cisplatin. After $24 \mathrm{~h}$, the cells were collected and luciferase assays were performed. The luciferase activity in control samples was normalized to 1.0. Error bars indicate standard deviations. The values shown represent the mean of at least three separate experiments. Significant differences are indicated by asterisks. ${ }^{*} \mathrm{P}<0.05$. (C) HCC SMMC7721 cells were incubated with indicated concentration of cisplatin for $24 \mathrm{~h}$ with or without pretreatment of PDTC (100 $\left.\mu \mathrm{M}\right)$ for $1 \mathrm{~h}$ and then harvested. The cell lysates were subjected to SDS-PAGE and blotted with anti-TERT antibody. A representative example of an experiment that was repeated three times is shown. (D) HCC SMMC7721 cells were transfected with pGL3B-TRTP plasmid and incubated with indicated concentration of cisplatin with or without pretreatment of PDTC $(100 \mu \mathrm{M})$ for $1 \mathrm{~h}$. After $24 \mathrm{~h}$, the cells were collected and luciferase assays were performed. The luciferase activity in control samples was normalized to 1.0. Error bars indicate standard deviations. The values shown represent the mean of at least three separate experiments. Significant differences are indicated by asterisks. ${ }^{*}$ P $<0.05$ (E) HCC SMMC7721 cells were cotransfected with pGL3B-TRTP plasmid and IKK-KM plasmid and then incubated with indicated concentration of cisplatin. After $24 \mathrm{~h}$, the cells were collected and luciferase assays were performed. The luciferase activity in control samples was normalized to 1.0. Error bars indicate standard deviations. The values shown represent the mean of at least three separate experiments. Significant differences are indicated by asterisks. ${ }^{*} \mathrm{P}<0.05$.

cells (27-29). Therefore, we examined whether NF-кB is involved in cisplatin-induced hTERT expression. First, we examined whether NF- $\mathrm{B}$ can be activated by low-dose cisplatin. SMMC7721 cells were treated with indicated concentrations of cisplatin for $24 \mathrm{~h}$ and then used to prepare lysates for Western blot analysis with anti-p65. As shown in Fig. 2A, cisplatin can induce nuclear translocation of NF-кB p65 protein. We then tested the effect of cisplatin on NF- $\mathrm{B}$ activity. SMMC7721 cells were transfected with the NF- $\mathrm{BB}$ luciferase reporter plasmid and incubated with indicated concentrations of cisplatin for $24 \mathrm{~h}$. The luciferase assays revealed that the $\mathrm{NF}-\kappa \mathrm{B}$ activity can be significantly enhanced by cisplatin in a dose-dependent manner. There is a 2.2-fold increase at $1 \mu \mathrm{g} / \mathrm{ml}$ of cisplatin (Fig. 2B). These results suggested that cisplatin can activate $\mathrm{NF}-\kappa \mathrm{B}$.

We next examined whether $\mathrm{NF}-\kappa \mathrm{B}$ is involved in the induction of hTERT expression by cisplatin. To test the role of NF- $\mathrm{NB}$ in the cisplatin-induced activation of hTERT expression, we pretreated SMMC7721 cells with PDTC $(100 \mu \mathrm{M})$, a known pharmacological inhibitor of NF- $\mathrm{BB}$ for $1 \mathrm{~h}$. In the present of PDTC, the cisplatin-induced the increasing in hTERT protein (Fig. 2C) was attenuated. The activity of hTERT promoter was also impaired by PDTC (Fig. 2D). In addition, we co-transfected SMMC7721 cells with pGL3B-TRTP and IKK-KM plasmid and then incubated with indicated concentration of cisplatin. After $24 \mathrm{~h}$, the cells were collected and luciferase assays were performed. As shown in Fig. 2E, cotransfecting with IKK-KM plasmid, the activity of hTERT promoter was dramatically decreased. These results further verify that $\mathrm{NF}-\kappa \mathrm{B}$ is involved in cisplatin-induced hTERT expression. As c-Myc is a downstream target of $\mathrm{NF}-\kappa \mathrm{B}$ and has been reported to up-regulate hTERT transcription (30), we investigated the effect of cisplatin on c-Myc. As shown in Fig. 3, c-Myc was not affected by cisplatin, indicating that c-myc is not involved in cisplatin-dependent up-regulation of hTERT. 


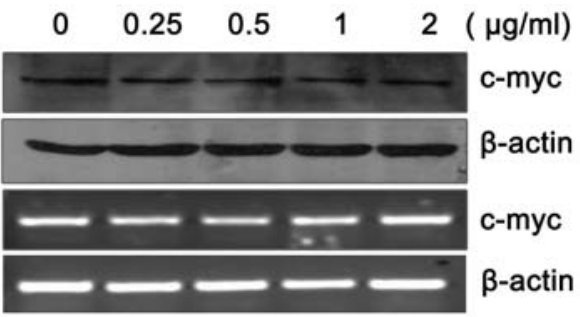

Figure 3. C-Myc has no effect on cisplatin-induced telomerase activity and hTERT expression in human HCC cells. HCC SMMC7721 cells were incubated with indicated concentration of cisplatin for $24 \mathrm{~h}$. Western botting and RT-PCR assays were performed to examine the effects of cisplatin on the expression of c-Myc. A representative example of an experiment that was repeated three times is shown.

Telomerase contribute to chemotherapy resistance in SMMC7721 cells. Several studies have indicated that hTERT had an anti-apoptotic activity in addition to its role in telomere length maintenance. Thus, it is of interest to investigate whether SMMC7721 cells can acquire inducible resistance to certain chemotherapeutic agents when preincubated with low-dose cisplatin. SMMC7721 cells were preincubated in $1 \mu \mathrm{g} / \mathrm{ml}$ cisplatin for $24 \mathrm{~h}$ and then treated with $5-\mathrm{FU}(65 \mu \mathrm{g} / \mathrm{ml})$ and epirubicin $(1 \mu \mathrm{g} / \mathrm{ml})$ for another $24 \mathrm{~h}$, respectively. The morphology of cells was observed and pictures were taken under a microscope. Then, the cells were harvested and used to prepare cell lysates. The lysates were subjected to SDSPAGE and blotted with anti-PARP antibody. As shown in Fig. 4A, control cells, but not preincubated cells, show significant cell death. Control cells revealed morphologic features typical of apoptosis, including cytoplasmic condensation, nuclear fragmentation and blebbing. These results were confirmed by immunoblotting, where control cells resulted in increased level of cleaved PARP (Fig. 4B).

We next examined whether inhibition of telomerase restored chemosensitivity of SMMC7721 cells when these cells were preincubated with low-dose cisplatin. SMMC7721 cells were infected with Ad-si/hTERT virus for $24 \mathrm{~h}$ and then preincubated in $1 \mu \mathrm{g} / \mathrm{ml}$ cisplatin for another $24 \mathrm{~h}$. After preincubation, cells were treated with $5-\mathrm{FU}(65 \mu \mathrm{g} / \mathrm{ml})$ and epirubicin $(1 \mu \mathrm{g} / \mathrm{ml})$ for $24 \mathrm{~h}$, respectively. WST-8 assay and DAPI staining were performed to detect cell death. As shown in Fig. 5A and B, Ad-si/hTERT can significantly inhibit hTERT expression and telomerase activity. Meanwhile, SMMC7721 cells infected with Ad-si/hTERT showed dramatic sensitivity to chemotherapeutic agents (Fig. 5C-E). Taken together, these results suggest that inducible resistance to certain chemotherapeutic agents can be acquired in SMMC7721 when telomerase is up-regulated by preincubation with low-dose cisplatin. Inhibition of telomerase can restore chemosensitivity of SMMC7721 cells to chemotherapeutic agents. Thus, telomerase contributed to chemotherapy resistance in SMMC7721 cells.

\section{Discussion}

The hTERT promoter contains binding sites for many transcription factors, including c-Myc, Sp1 and NF-кB and transcriptional regulation of hTERT is believed to be one of the major mechanisms of telomerase regulation in human
A

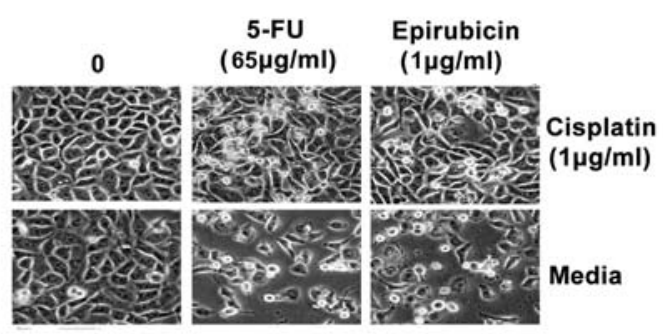

B

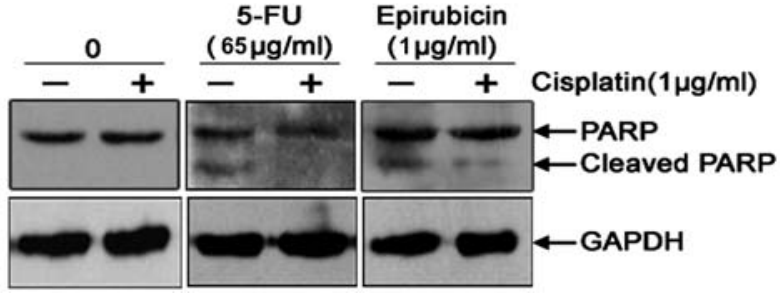

Figure 4. Low-dose cisplatin-induced HCC cells were more resistant to chemotherapy. HCC SMMC7721 cells were pre-incubated in $1 \mu \mathrm{g} / \mathrm{ml}$ cisplatin for $24 \mathrm{~h}$ and then treated with 5-FU $(65 \mu \mathrm{g} / \mathrm{ml})$ and epirubicin $(1 \mu \mathrm{g} / \mathrm{ml})$ for another $24 \mathrm{~h}$, respectively. (A) The morphology of cells was observed and pictures were taken under the microscope. (B) Western blotting was carried out using specific antibodies against PARP and $\beta$-actin, respectively. $\beta$-actin was used as the protein loading control.

cells. However, there is little information on the regulation of telomerase by cisplatin and the relationship between telomerase and chemosensitivity in cancer cells. We report here that low-dose cisplatin induces hTERT expression and up-regulation of telomerase contributed to chemotherapy resistance in hepatocellular carcinoma cell line SMMC7721.

We first demonstrated that low-dose cisplatin induces hTERT expression in SMMC7721 cells at the transcriptional level (Fig. 1), as it was reported previously that long-term exposure of colorectal carcinoma cells to cisplatin results in increased telomerase activity (18). We also observed that $\mathrm{NF}-\kappa \mathrm{B}$ was responsible for the cisplatin-induced transcriptional activation of hTERT (Fig. 2), as cisplatin can

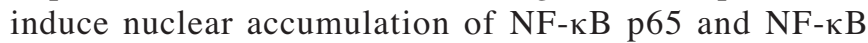
activation. Inhibition of NF-кB (PDTC or cotransfected with IKK-KM plasmid) significantly impaired cisplatin-induced up-regulation of telomerase activity. Therefore, cisplatin upregulates hTERT expression via NF- $\kappa \mathrm{B}$ activation. This is supported by previous studies that transcriptional activation of hTERT is through the NF-кB pathway in HTLV-I-transformed cells (31). In addition, our results were in line with a previous study that NF- $\kappa \mathrm{B}$ could be activated by cisplatin in HCC cells (27). C-Myc is a downstream target of NF- $\mathrm{KB}$ that upregulates hTERT transcription (30), it remains to be elucidated whether NF- $\mathrm{BB}$ may regulate hTERT expression via c-Myc. Our results suggest that c-Myc did not affect cisplatin-induced hTERT expression (Fig. 3). Thus, our results clearly show that transcriptional level regulation of hTERT is one of the major mechanisms of telomerase activation. NF-кB was responsible for the cisplatin-induced transcriptional activation of hTERT.

What is the functional relevance for cisplatin-induced telomerase up-regulation? Most cytotoxic agents including 
A

\section{control Ad-null Ad-si/hTERT}
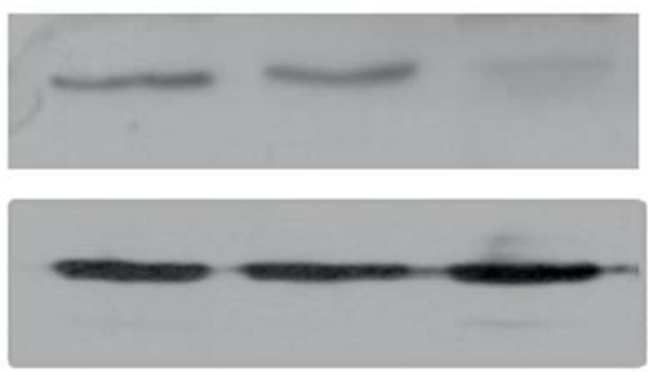

B

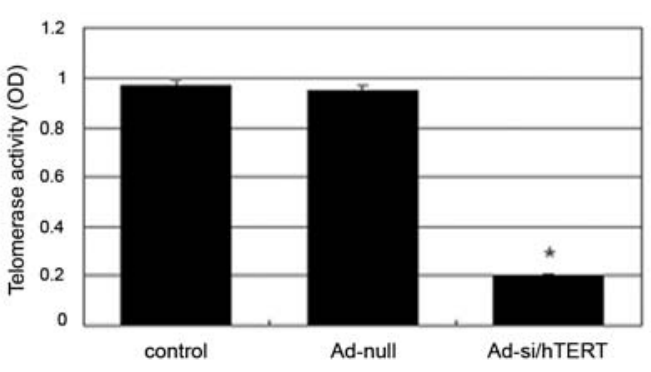

C

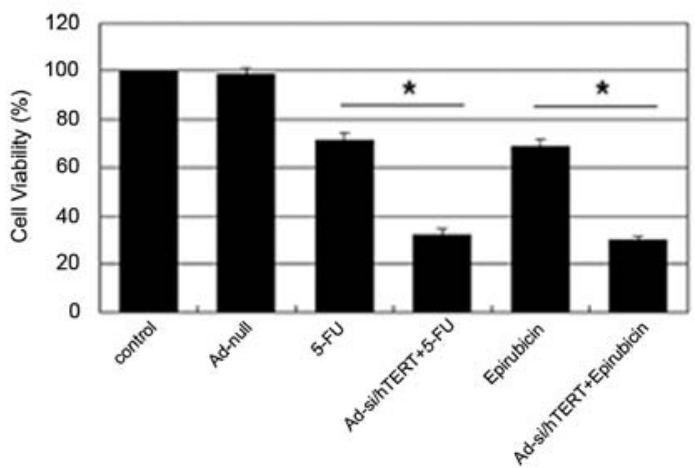

D

hTERT

control

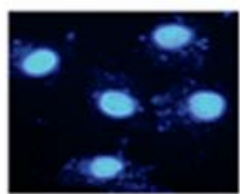

Ad-si/hTERT

\section{$\beta$-actin}

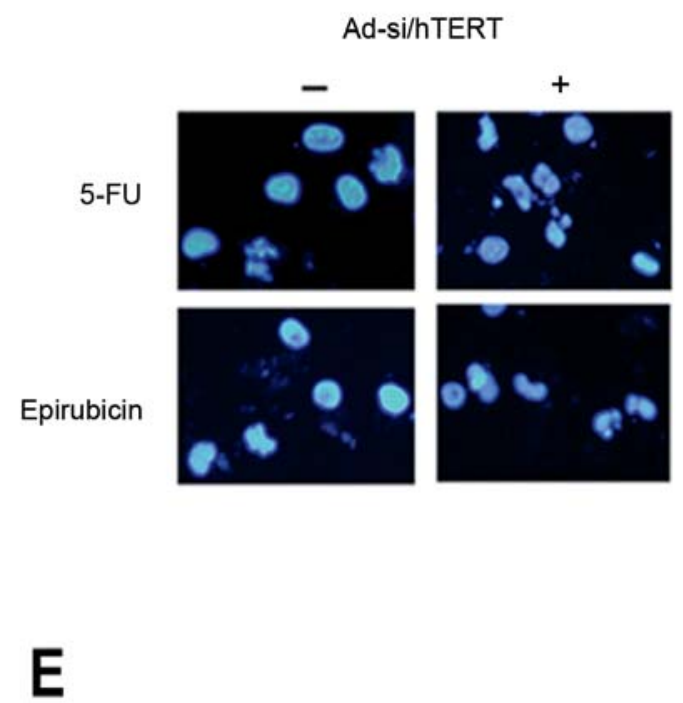

Figure 5. Inhibition of telomerase significantly increased cell sensitivity to chemotherapeutic agents. (A) To examine the effect of AD-si/hTERT on hTERT expression, cell lysates were subjected to SDS-PAGE and blotted with anti-TERT antibody. (B) TRAP-ELISA assay was used to assess the effect of ADsi/hTERT on telomerase activity. (C) SMMC7721 cells were infected with Ad-si/hTERT virus for $24 \mathrm{~h}$ and then preincubated in $1 \mu \mathrm{g} / \mathrm{ml}$ cisplatin for another $24 \mathrm{~h}$. After preincubation, cells were treated with 5-FU $(65 \mu \mathrm{g} / \mathrm{ml})$ and epirubicin $(1 \mu \mathrm{g} / \mathrm{ml})$ for $24 \mathrm{~h}$, respectively. Cell viability was determined by WST-8 assay. The viability of the untreated cells was regarded as $100 \%$. Points, mean of three independent experiments. (D) DAPI staining was used to identify morphological features of cell death such as nuclear condensation and fragmentation. (E) Quantitative analysis of chemotherapy-induced apoptosis. DAPIstained cells were counted in 5 fields $(n=5, P<0.05)$.

cisplatin induce apoptosis in tumor cells and reduced apoptosis induction is associated with drug resistance (32). In the present study, SMMC7721 cells were preincubated with $1 \mu \mathrm{g} / \mathrm{ml}$ for $24 \mathrm{~h}$ and then followed by treatment with high concentration of 5-FU $(65 \mu \mathrm{g} / \mathrm{ml})$ and epirubicin $(1 \mu \mathrm{g} / \mathrm{ml})$, respectively.
Comparing with un-preincubated control cell, those preincubated cells showed more resistance to chemotherapeutic agent-induced apoptosis (Fig. 4). Inhibition of telomerase increased chemosensitivity of those pre-incubated cells to chemotherapeutic agents (Fig. 5). Thus, in this experiment 
up-regulation of telomerase induced by low-dose cisplatin may reduce chemosensitivity of SMMC7721 cells to the high concentration of chemotherapeutic agents. It has been reported that up-regulation of telomerase elongated telomeres and protected cancer cells from chemotherapeutic agent-induced cell death. Long-term exposure of colorectal carcinoma cells to cisplatin results in increased telomerase activity and drug resistance with elongated telomeres (18) and hTERTtransfected K562 cells had elongated telomeres, and were significantly more resistant to double-stranded DNA breakinduced apoptosis by IR and VP-16 (33). Furthermore, previous studies have shown that telomerase has an antiapoptotic role and conferred cancer cells resistance to chemotherapeutic agents and stress-induced apoptosis, which is distinct from its telomere-maintenance function (34). Moreover, it was previously reported that telomerase activity can be induced in the response to DNA damage agents $(18,35)$ and has roles in helping cell survive and enhancing genomic stability (36). Some studies have shown that shortened telomeres impair double-strand DNA break repair and enhance sensitivity to IR and doxorubicin in telomerase RNA null mice $(37,38)$. Thus, in this experiment, up-regulation of telomerase may have advantage to maintain telomere integrity and stabilize damaged chromosomes and to protect cells from stress-induced apoptosis dependent or independent of telomerase enzymatic activity.

Resistance of tumor cells to chemotherapy treatment represents one of the major causes of failure in cancer therapy and appears to be the result of the increased expression of defense factors, as well as the alterations of factors involved in cellular response to DNA damage. These factors include decreased cellular accumulation of drugs (39), increased DNA repair (40) and impaired susceptibility to apoptosis (41). Decreased cellular accumulation of the drug will cause low concentration of chemotherapeutic agents. Up-regulation of telomerase may enhance genomic stability and protect cells from apoptosis induction. It has been previously reported that that hTERT expression in telomerase-negative cells decreases their sensitivity to topoisomerase inhibitors such as etoposide (42). In our experiment, pre-incubation with low-dose cisplatin reduced chemosensitivity of SMMC7721 cells to the high concentration of anti-cancer drugs, very likely due to increased telomerase activity. This alteration modulates the effects of the chemotherapeutic agents. The potential roles of telomerase induced by low-dose cisplatin in the development of cancer chemotherapeutic resistance need future experimental and clinical examination. Our results also demonstrate that combination of telomerase inhibition and traditional treatment with cancer therapeutic agents is a potent new approach to treating hepatocarcinoma.

\section{Acknowledgements}

We thank Dr Chuanshu Huang and Jiyue Zhu for providing us with plasmids. This project was supported by the Special Funds for National Natural Science Foundation of China (Grant No: 30700981, 30801347, 30870974), the Commission of Science and Technology of Shanghai Municipality (Grant No: 045407047, 08XD14003) and National Key Sci-Tech Special Project of China (Grant No: 2008ZX10002-019, 2008ZX10002-025).

\section{References}

1. Greider $\mathrm{CW}$ and Blackburn EH: Identification of a specific telomere terminal transferase activity in Tetrahymena extracts. Cell 43: 405-413, 1985.

2. Greider CW and Blackburn EH: A telomeric sequence in the RNA of Tetrahymena telomerase required for telomere repeat synthesis. Nature 337: 331-337, 1989.

3. Kim NW, Piatyszek MA, Prowse KR, Harley CB, West MD, Ho PL, Coviello GM, Wright WE, Weinrich SL and Shay JW: Specific association of human telomerase activity with immortal cells and cancer. Science 266: 2011-2015, 1994.

4. Shay JW and Bacchetti S: A survey of telomerase activity in human cancer. Eur J Cancer 33: 787-791, 1997.

5. Takakura M, Kyo S, Kanaya T, Tanaka M and Inoue M: Expression of human telomerase subunits and correlation with telomerase activity in cervical cancer. Cancer Res 58: 1558-1561, 1998.

6. Kyo S, Kanaya T, Takakura M, Tanaka M and Inoue M: Human telomerase reverse transcriptase as a critical determinant of telomerase activity in normal and malignant endometrial tissues. Int J Cancer 80: 60-63, 1999.

7. Kyo S, Kanaya T, Takakura M, Tanaka M, Yamashita A, Inoue H and Inoue M: Expression of human telomerase subunits in ovarian malignant, borderline and benign tumors. Int J Cancer 80: 804-809, 1999.

8. Cong YS, Wen J and Bacchetti S: The human telomerase catalytic subunit hTERT: organization of the gene and characterization of the promoter. Hum Mol Genet 8: 137-142, 1999.

9. Horikawa I, Cable PL, Afshari C and Barrett JC: Cloning and characterization of the promoter region of human telomerase reverse transcriptase gene. Cancer Res 59: 826-830, 1999.

10. Meyerson M, Counter CM, Eaton EN, Ellisen LW, Steiner P, Caddle SD, Ziaugra L, Beijersbergen RL, Davidoff MJ, Liu Q, Bacchetti S, Haber DA and Weinberg RA: hEST2, the putative human telomerase catalytic subunit gene, is up-regulated in tumor cells and during immortalization. Cell 90: 785-795, 1997.

11. Takakura M, Kyo S, Kanaya T, Hirano H, Takeda J, Yutsudo M and Inoue M: Cloning of human telomerase catalytic subunit (hTERT) gene promoter and identification of proximal core promoter sequences essential for transcriptional activation in immortalized and cancer cells. Cancer Res 59: 551-557, 1999.

12. Lu C, Fu W and Mattson MP: Telomerase protects developing neurons against DNA damage-induced cell death. Brain Res Dev Brain Res 131: 167-171, 2001.

13. Holt SE, Glinsky VV, Ivanova AB and Glinsky GV: Resistance to apoptosis in human cells conferred by telomerase function and telomere stability. Mol Carcinog 25: 241-248, 1999.

14. Faraoni I, Turriziani M, Masci G, De Vecchis L, Shay JW, Bonmassar E and Graziani G: Decline in telomerase activity as a measure of tumor cell killing by antineoplastic agents in vitro. Clin Cancer Res 3: 579-585, 1997.

15. Asai A, Kiyozuka Y, Yoshida R, Fujii T, Hioki K and Tsubura A: Telomere length, telomerase activity and telomerase RNA expression in human esophageal cancer cells: correlation with cell proliferation, differentiation and chemosensitivity to anticancer drugs. Anticancer Res 18: 1465-1472, 1998.

16. Lin Z, Lim S, Viani MA, Sapp M and Lim MS: Down-regulation of telomerase activity in malignant lymphomas by radiation and chemotherapeutic agents. Am J Pathol 159: 711-719, 2001.

17. Sato N, Mizumoto K, Kusumoto M, Nishio S, Maehara N, Urashima T, Ogawa T and Tanaka M: Up-regulation of telomerase activity in human pancreatic cancer cells after exposure to etoposide. Br J Cancer 82: 1819-1826, 2000.

18. Kuranaga N, Shinomiya N and Mochizuki H: Long-term cultivation of colorectal carcinoma cells with anti-cancer drugs induces drug resistance and telomere elongation: an in vitro study. BMC Cancer 1: 10, 2001.

19. Moriarty TJ, Dupuis S and Autexier C: Rapid upregulation of telomerase activity in human leukemia HL-60 cells treated with clinical doses of the DNA-damaging drug etoposide. Leukemia 16: $1112-1120,2002$

20. Siddik ZH: Cisplatin: mode of cytotoxic action and molecular basis of resistance. Oncogene 22: 7265-7279, 2003.

21. Roberts LR and Gores GJ: Hepatocellular carcinoma: molecular pathways and new therapeutic targets. Semin Liver Dis 25: 212-225, 2005

22. Burger AM, Double JA and Newell DR: Inhibition of telomerase activity by cisplatin in human testicular cancer cells. Eur J Cancer 33: 638-644, 1997. 
23. Akiyama M, Horiguchi-Yamada J, Saito S, Hoshi Y, Yamada O, Mizoguchi $\mathrm{H}$ and Yamada $\mathrm{H}$ : Cytostatic concentrations of anticancer agents do not affect telomerase activity of leukaemic cells in vitro. Eur J Cancer 35: 309-315, 1999.

24. Wang S and Zhu J: Evidence for a relief of repression mechanism for activation of the human telomerase reverse transcriptase promoter. J Biol Chem 278: 18842-18850, 2003.

25. Chen J, Yan Y, Li J, Ma Q, Stoner GD, Ye J and Huang C: Differential requirement of signal pathways for benzo[a]pyrene (B[a]P)-induced nitric oxide synthase (iNOS) in rat esophageal epithelial cells. Carcinogenesis 26: 1035-1043, 2005.

26. Takakura M, Kyo S, Inoue M, Wright WE and Shay JW: Function of AP-1 in transcription of the telomerase reverse transcriptase gene (TERT) in human and mouse cells. Mol Cell Biol 25: 8037-8043, 2005.

27. Chuang SE, Yeh PY, Lu YS, Lai GM, Liao CM, Gao M and Cheng AL: Basal levels and patterns of anticancer drug-induced activation of nuclear factor-kappaB (NF-kappaB), and its attenuation by tamoxifen, dexamethasone, and curcumin in carcinoma cells. Biochem Pharmacol 63: 1709-1716, 2002.

28. Li Y, Ahmed F, Ali S, Philip PA, Kucuk O and Sarkar FH: Inactivation of nuclear factor kappaB by soy isoflavone genistein contributes to increased apoptosis induced by chemotherapeutic agents in human cancer cells. Cancer Res 65: 6934-6942, 2005.

29. Yeh PY, Chuang SE, Yeh KH, Song YC and Cheng AL: Involvement of nuclear transcription factor-kappa B in low-dose doxorubicin-induced drug resistance of cervical carcinoma cells. Biochem Pharmacol 66: 25-33, 2003.

30. Sheng WY, Chen YR and Wang TC: A major role of PKC theta and NFkappaB in the regulation of hTERT in human T lymphocytes. FEBS Lett 580: 6819-6824, 2006.

31. Sinha-Datta U, Horikawa I, Michishita E, Datta A, Sigler-Nicot JC, Brown M, Kazanji M, Barrett JC and Nicot C: Transcriptional activation of hTERT through the NF-kappaB pathway in HTLV-I-transformed cells. Blood 104: 2523-2531, 2004.

32. Zunino F, Perego P, Pilotti S, Pratesi G, Supino R and Arcamone F: Role of apoptotic response in cellular resistance to cytotoxic agents. Pharmacol Ther 76: 177-185, 1997.

33. Akiyama M, Yamada O, Kanda N, Akita S, Kawano T, Ohno T, Mizoguchi H, Eto Y, Anderson KC and Yamada H: Telomerase overexpression in K562 leukemia cells protects against apoptosis by serum deprivation and double-stranded DNA break inducing agents, but not against DNA synthesis inhibitors. Cancer Lett 178: 187-197, 2002
34. Gorbunova V, Seluanov A and Pereira-Smith OM: Expression of human telomerase (hTERT) does not prevent stress-induced senescence in normal human fibroblasts but protects the cells from stress-induced apoptosis and necrosis. J Biol Chem 277: 38540-38549, 2002.

35. Neuhof D, Ruess A, Wenz F and Weber KJ: Induction of telomerase activity by irradiation in human lymphoblasts. Radiat Res 155: 693-697, 2001.

36. Sharma GG, Gupta A, Wang H, Scherthan H, Dhar S, Gandhi V, Iliakis G, Shay JW, Young CS and Pandita TK: hTERT associates with human telomeres and enhances genomic stability and DNA repair. Oncogene 22: 131-146, 2003.

37. Lee KH, Rudolph KL, Ju YJ, Greenberg RA, Cannizzaro L, Chin L, Weiler SR and DePinho RA: Telomere dysfunction alters the chemotherapeutic profile of transformed cells. Proc Natl Acad Sci USA 98: 3381-3386, 2001

38. Wong KK, Chang S, Weiler SR, Ganesan S, Chaudhuri J, Zhu C, Artandi SE, Rudolph KL, Gottlieb GJ, Chin L, Alt FW and DePinho RA: Telomere dysfunction impairs DNA repair and enhances sensitivity to ionizing radiation. Nat Genet 26 : $85-88$, 2000.

39. Gately DP and Howell SB: Cellular accumulation of the anticancer agent cisplatin: a review. Br J Cancer 67: 1171-1176, 1993.

40. Mistry P, Kelland LR, Abel G, Sidhar S and Harrap KR: The relationships between glutathione, glutathione-S-transferase and cytotoxicity of platinum drugs and melphalan in eight human ovarian carcinoma cell lines. Br J Cancer 64: 215-220, 1991.

41. Eastman A and Schulte N: Enhanced DNA repair as a mechanism of resistance to cis-diamminedichloroplatinum(II). Biochemistry 27: 4730-4734, 1988.

42. Ludwig A, Saretzki G, Holm PS, Tiemann F, Lorenz M, Emrich T, Harley CB and von Zglinicki T: Ribozyme cleavage of telomerase mRNA sensitizes breast epithelial cells to inhibitors of topoisomerase. Cancer Res 61: 3053-3061, 2001. 